\title{
Where do questions begin? - phrase-initial boundary tones in Hungarian polar questions
}

\author{
Katalin Mády ${ }^{1}$, Ádám Szalontai ${ }^{1,2}$ \\ ${ }^{1}$ Research Institute for Linguistics, Hungarian Academy of Sciences, Budapest, Hungary \\ ${ }^{2}$ Eötvös Loránd University, Budapest, Hungary \\ \{mady|szalontai\}enytud.hu
}

\begin{abstract}
Hungarian prosody is left-headed, as suggested by the placement of the accent on the initial syllable on the level of prosodic words and the placement of the strongest pitch accent on the first accented word of the prosodic phrase. Earlier studies have pointed out that the left edge of the intonational phrase can bear a phrase-initial boundary tone that distinguishes between stringidentical $w h$-interrogatives and $w h$-exclamatives. In this paper, two other string-identical sentence types, polar questions and declaratives, are investigated with respect to their prosodic features. Polar questions were characterised by a higher f0 maximum and a lower sentence-initial f0 than declaratives. The only pitch accent within the sentence was low, whereas declaratives had falling pitch accents. Sentence-final fo and the pitch level of the accented syllable did not show a consistent pattern across speakers. It is concluded that low sentence-initial f0 together with the high $\mathrm{t}$ ! one on the penultimate syllable is a relevant marker of polar questions in Hungarian.

Index Terms: intonation, phrase-initial boundary tone, polar question, declarative, sentence type.
\end{abstract}

\section{Introduction}

\subsection{Left-headedness in Hungarian prosody and syntax}

Hungarian prosody is left-headed, as suggested by the placement of the accent on the initial syllable on the level of the prosodic words and the placement of the pitch accent on the first accented syllable of the prosodic phrase [1, 2]. [3] who builds on earlier observations by [4] and [5] suggest a mapping rule between prosody and syntax that aligns the left edge of the syntactic phrase with the left edge of the phonological phrase. [6] makes a similar claim, namely that the nuclear stress rule of [7] operates in a direction opposite to that in English in that the primary phrasal stress falls on the left edge. This correlates well with the structure of the Hungarian clause, which can be divided into two basic units, first the topic (optional) which is linearly followed by the predicate (obligatory) at the left edge of which is the focus position, bearing the primary a! ccent. If a focussed constituent is present, it leads to the deaccentuation of the verb and the post-verbal elements within the same prosodic unit.
(1) [Top Tegnap] [Pred [Foc János] ette meg a levest] yesterday John ate PV the soup
'Yesterday it was John who ate the soup.'

Due to the obligatory nature of the predicate, it is this syntactic structure that best correlates with higher level prosodic units, namely the intonational phrase. The word order of the Hungarian clause is determined by information structure: the constituent which is focussed is placed in the immediate pre-verbal position, thus receiving the main pitch accent in the clause [6]. In neutral sentences (those with broad focus) this position is usually occupied by the verbal prefix (PV in (1) above), which bears the main pitch accent in these cases. However if there is a focussed constituent and a verbal prefix, the prefix occurs immediately after the verb.

\subsection{Sentence types and prosody in Hungarian}

In theoretical classifications of clause or sentence types, the set of basic sentence types includes declaratives, interrogatives and imperatives, whereas exclamatives are considered to be outside of this set $[8,9]$. The basis for this distinction is that while basic sentence types are definable with the help of a small number of necessary and sufficient formal criteria in the languages where they occur, there do not seem to be equally available unambiguous formal criteria for setting apart structures that express the meaning attributed to exclamatives. Instead, exclamatives can be only characterised by their intonational pattern.

Exclamatives were described as having a "high tone followed by a slow descent" by [10] previously. In a recent production study, string-identical $w h$-interrogatives and a particular type of wh-exclamatives were compared with respect to their tonal differences [11]. The analysis was based on tonal categories such as phrase-initial and phrase-final boundary tones and pitch accent patterns along with a parametric analysis of f0. Although it was expected that $w h$-exclamatives contained a higher f0 maximum than $w h$-interrogatives and a higher phrasefinal boundary tone, they had actually lower fo maxima than $w h$-interrogatives, and there was no difference between the sentence-final f0 values. The main distinction was the shape of the (only) pitch accent on the $w h$-word: exclamatives had rising accents, interrogatives falling ones. It was not clear whether the accent patterns were the primary cues for the into! national distinction, or whether they were a consequence of different phrase-initial boundary tones as had been proposed by [12] for $w h$-interrogatives. A follow-up perception experiment [13] with deaccented particles before the pitch-accented $w h$-word showed that sentence-initial fo enhanced sentence-type identification, whereas the pitch accent pattern and sentence-final fo did not.

Another example of sentence types that are only distinguished by their intonational patterns are yes/no interrogatives and declaratives. [14] and [15] suggest that there is an $\mathrm{L}^{*}$ accent on the verb and an $\mathrm{H} \mathrm{L} \%$ boundary tone spread over the penultimate and final syllables. According to [16], the perception as a question is enhanced both by a higher $\mathrm{f} 0$ and a relatively late 
timing of the peak within the penultimate syllable. It is not clear whether the $\mathrm{L}^{*}$ pitch accent and a phrase-initial boundary tone contribute to the intonational distinction between these sentence types.

For the prosodic description of the two sentence types, the following questions are of interest: (1) Is there a sentence-initial tonal distinction? (2) Does the rising-falling sentence-final tone in interrogatives result in higher f0 due to truncation? (3) Are the $\mathrm{L}^{*}$ accent and the $\mathrm{H}$ tone in questions indeed lower and higher in terms of absolute values than the corresponding values in declaratives?

\section{Material and methods}

\subsection{Material}

The study used five pairs of string-identical sentences with the structure in (2):

(2) De most végül lámpa is van náluk ./? But now in the end lamp also be.3sG with them 'But in the end they have a lamp with them.'

'But in the end do they have a lamp with them?'

The first three items of the string De, most, and végül are unaccented discourse particles. These were included to provide enough phonological space for the sentence-initial boundary tones to manifest independently of the main pitch accent which in this sentence falls on lampa 'lamp', the constituent in the focus position of the predicate. The combined length of these discourse markers was 4 syllables in all target sentences. The target sentences were preceded by disambiguating contexts.

The expected prosodic pattern for both questions and declaratives was to contain one single intonational phrase, 2-3 deaccented particles (4 syllables altogether) and one pitch accent on the focussed word with post-focal deaccentuation. The last pitch accent preceded the sentence-final boundary by 4-8 syllables, which typically resulted in an overall rising f0 between the accented and the penultimate syllable for questions, and a flat or falling contour for declaratives. Sentences that contained more than one prosodic phrases or several pitch accents were excluded from further analysis. 296 utterances in total were analysed.

There were 7 subjects (all female) with a mean age of 21 years. Their task was to read aloud sentences that were presented to them on a screen using the experimental software SpeechRecorder [17]. Each pair of sentences was presented five times in individually randomized order.

\subsection{Methods}

The following parameters were investigated:

- sentence-initial f0 (on the first vowel),

- sentence-final f0 (on the last vowel),

- lowest f0 on the accented syllable,

- f0 maximum within the sentence.

F0 was measured using Praat's standard autocorrelation method with a window length of $30 \mathrm{~ms}$ and a window shift by $5 \mathrm{~ms}$. Tones with an f0 minimum below $130 \mathrm{~Hz}$ were regarded as creaky-voiced.

Additionally, pitch accents were labelled with respect to their pattern. Categorisation relied on the actual fo movements rather than on phonological labels.
Mixed models with the random effects subject and sentence were carried out for each parameter. Significance was tested by the Anova ( ) function of the car package in R, and the significance level was set to $p<0.05$. Hertz values were transformed into semitones.

\section{Results}

Figure 1 shows typical examples of a declarative and an interrogative sentence. The declarative contains one pitch accent that falls on the first syllable of the word LÁMpa 'lamp'. The falling accent is typically found in pre-verbal elements within the predicate [18]. The polar question contains one pitch accent on the same syllable which has a low tone. The f0 maximum is associated with the penultimate syllable.
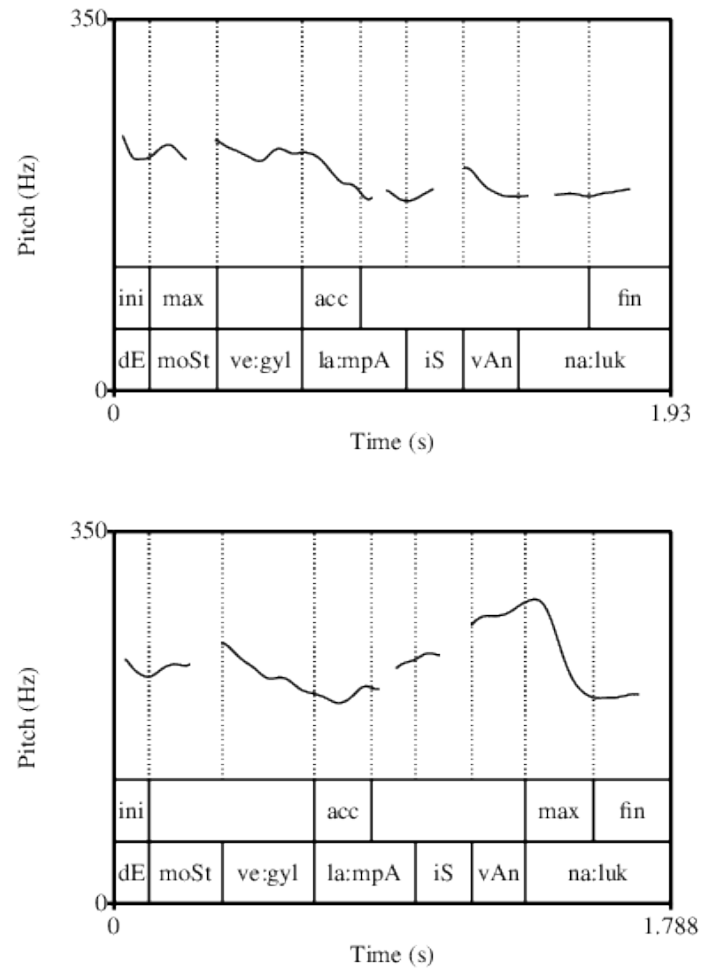

Figure 1: Pitch contour of the declarative sentence 'But in the end they have a lamp with them' (top) and the polar question 'But in the end do they have a lamp with them?' (bottom). Measurements described in Section 2 were based on the syllables marked as ini, acc, max, fin.

\subsection{Sentence-initial fo}

There was an overall tendency for sentence-initial f0 to be lower in interrogatives $($ mean $=206 \mathrm{~Hz})$ than in declaratives $($ mean $=$ $224 \mathrm{~Hz}$, difference: 1.48 semitones, $p<0.005$ ). The tendency was present in 6 out of 7 speakers (see Fig. 2). Intra-speaker differences ranged from -0.03 to 5.88 semitones. Occurrences of creaky voice were rather low in this position (3\% of all cases), and they were evenly distributed between declaratives and polar questions. 


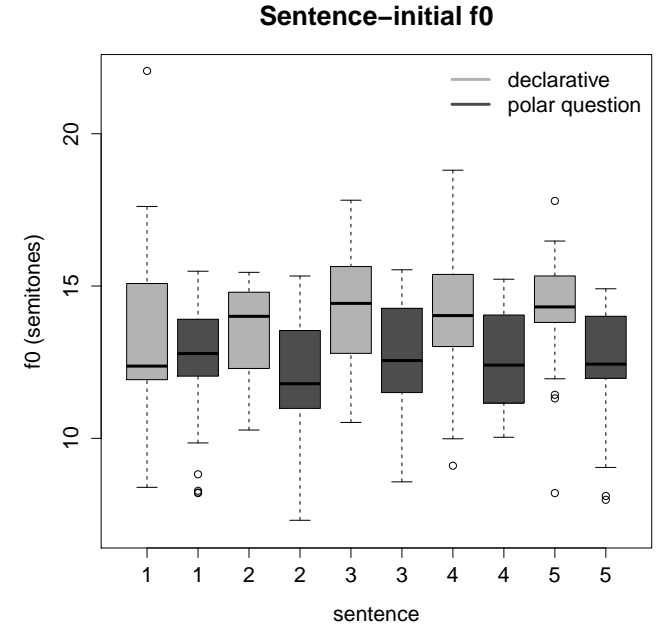

Sentence-initial f0

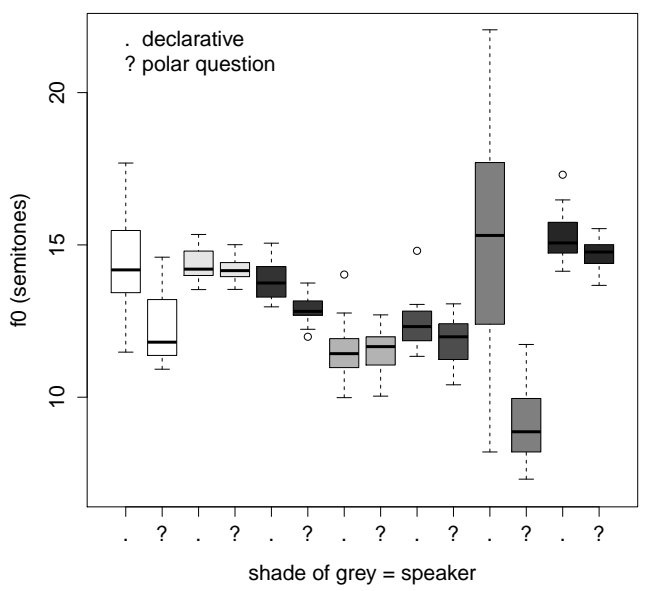

Figure 2: Sentence-initial fo in semitones. Pairwise comparison of sentences (top) and speakers (bottom).

\subsection{Sentence-final fo}

As is shown in Fig. 3, sentence-final f0 in interrogatives was realised somewhat lower (mean $=185 \mathrm{~Hz}$ ) than in declaratives $(190 \mathrm{~Hz}$, difference: 0.48 semitones, $p<0.005)$. This tendency was present in 4 out of 7 speakers. Intra-speaker differences ranged from -1.82 to 4.42 semitones. $34 \%$ of all sentencefinal syllables were produced with creaky voice, and their occurrences in the two sentence types were equal.

\subsection{F0 maximum}

The maximal f0 was significantly higher in questions than in declaratives $(269 \mathrm{~Hz}$ vs. $248 \mathrm{~Hz}, 1.39$ semitones, $p<0.005$, see Fig. 4). One out of 7 speakers showed an opposite pattern. Intra-speaker differences ranged from -3.13 to 1.88 semitones, and the voicing was always modal.

The maximal pitch in polar questions is presumably perceived even higher than the actual f0 suggests, since the maximum appears later in the sentence than in declaratives, and it is
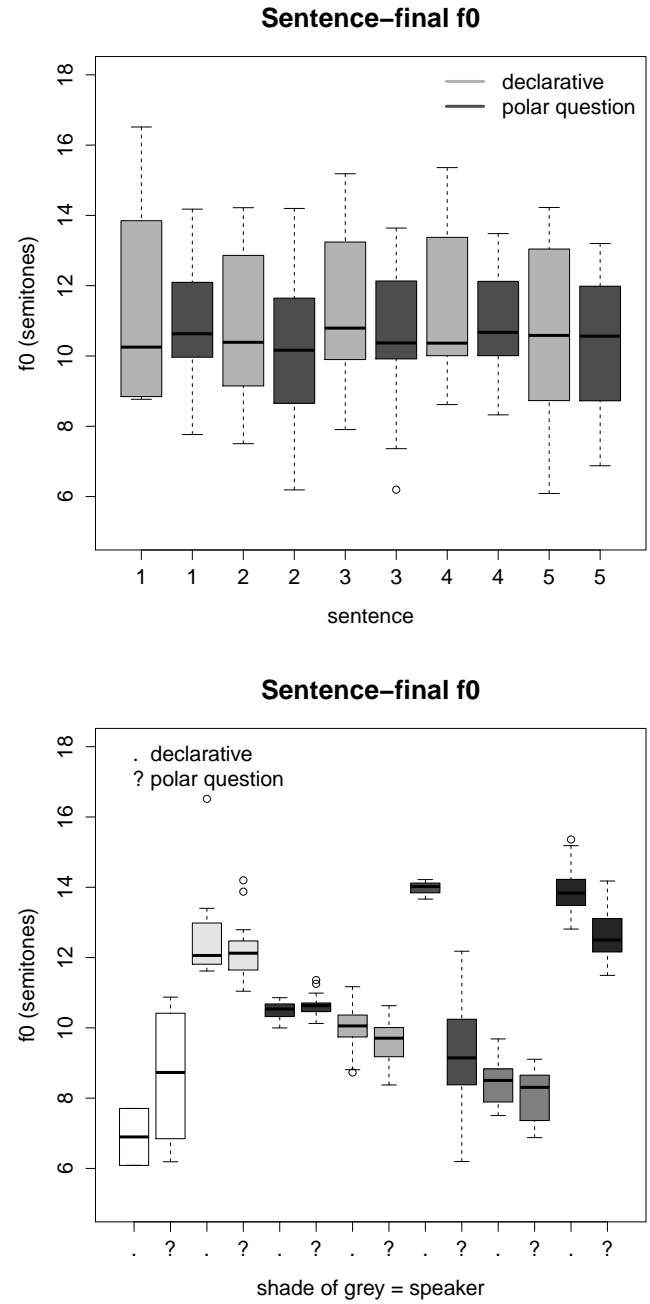

Figure 3: Sentence-final fo in semitones. Pairwise comparison of sentences (top) and speakers (bottom).

relatively higher compared to the declination line.

\subsection{Pitch accent}

Declaratives and polar questions are characterised by different pitch accents. The default pitch accent for focussed words in declaratives is a falling one, typically $\mathrm{H}^{*}+\mathrm{L}$, see $[18,19]$. Polar questions are realised with low or rising accents [16, 14]. In order to test whether the lowness of the f0 of the pitch accent is relevant for the distiction, the lowest fo on the accented syllable was measured.

As demonstrated in Fig. 5, there was no clear tendency across speakers with respect to local fo minima. The mean f0 was slightly higher for declaratives $(187 \mathrm{~Hz})$ than for questions (184 Hz, $p=0.02$ ), but this is reflected only in 4 out of 7 speakers, and the mean difference was only 0.2 semitones which is only slightly above the just noticeable difference. The intraspeaker difference ranged from -0.42 to 1.72 . Creaky voicing occurred in $7 \%$ of all questions, whereas it was half as frequent in declaratives. 


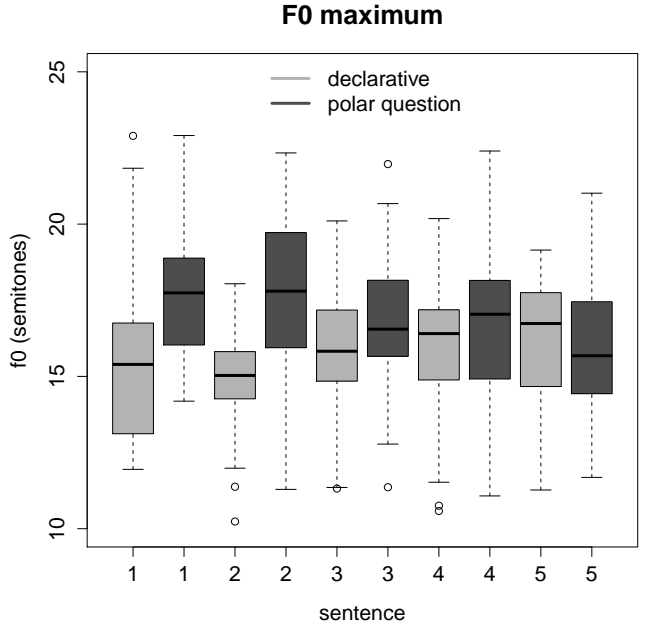

F0 maximum

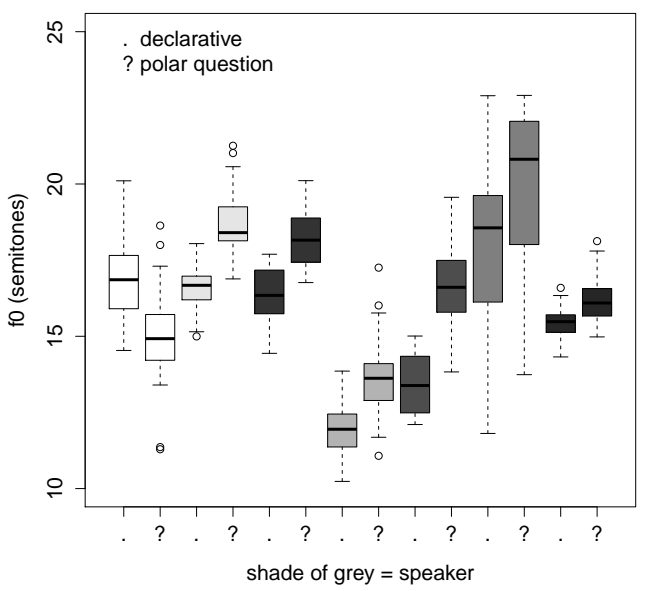

Figure 4: FO maximum in semitones. Pairwise comparison of sentences (top) and speakers (bottom).

\section{Discussion and conclusions}

The above results show that string-identical polar questions and declaratives differ both in terms of their tonal pattern and their f0 parameters. A consistent intra-speaker pattern was only observed for sentence-initial f0 that was lower and the overall fo maximum that was higher in questions. Speakers did not show a homogeneous pattern with respect to the utilisation of sentencefinal f0 and the local f0 minimum on the pitch-accented vowel.

As was said in the Introduction, string-identical $w h$ interrogatives and exclamatives are distinguished by higher sentence-initial f0 and higher f0 maxima for interrogatives, whereas sentence-final f0 does not play a role. The present data also show a higher f0 maximum for interrogatives, but a lower sentence-initial f0. Thus, it cannot be generalised that interrogatives were marked by higher sentence-initial f0 altogether, but it seems that sentence-initial $\mathrm{f} 0$ is indeed relevant for the sentence type distinction. Sentence-final f0, however, is rather inhomogeneous and is thus not expected to be a crucial marker for polar questions and declaratives. These results further corroborate the
F0 minimum on pitch accented vowel

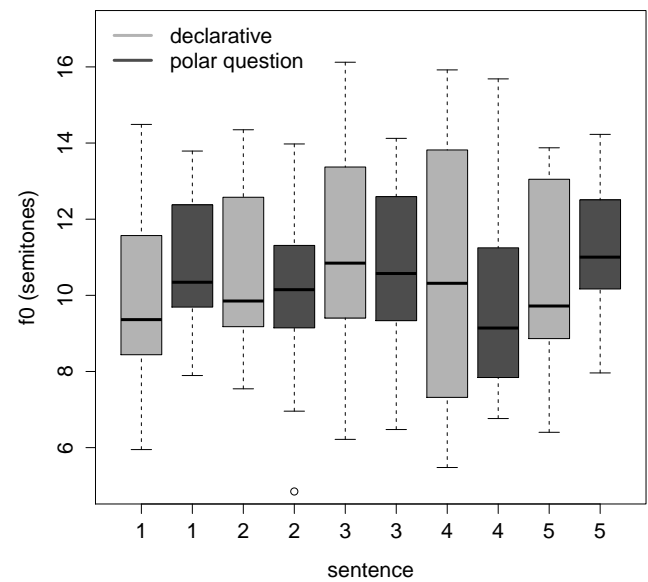

F0 minimum on pitch accented vowe

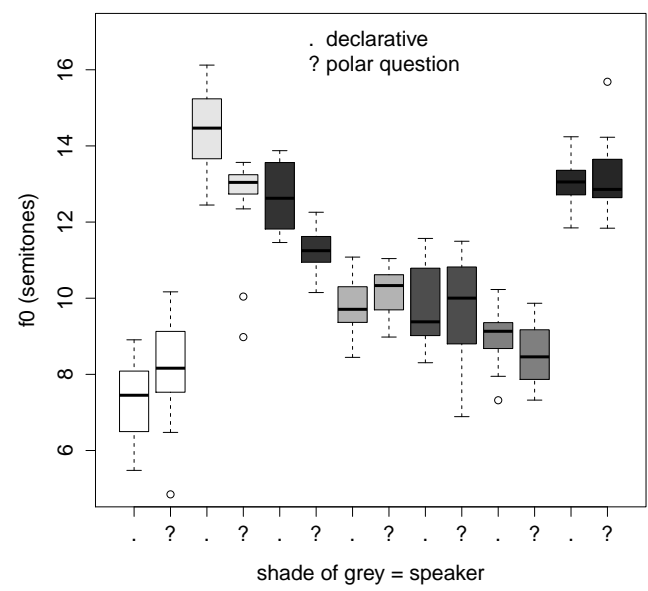

Figure 5: Local f0 minimum in pitch-accented vowels. Pairwise comparison of sentences (top) and speakers (bottom).

importance of the the left edge of prosodic units in Hungarian.

Two questions need further investigation in the close future: (1) Can the perceptual relevance of phrase-initial boundary tones for polar questions and declaratives be stated? (2) Is a high f0 maximum generally characteristic for interrogatives, and if yes, is it a linguistic or a pragmatic feature?

\section{Acknowledgements}

The study was supported by the Hungarian Scientific Research Fund $(101050,100804)$ and the Momentum program of the Hungarian Academy of Sciences, project title Interaction of linguistic subsystems in the production and perception of scope. Thanks to Zsuzsanna Bárkányi and Beáta Gyuris for their support with the creation and the collection of the data. 


\section{References}

[1] L. Hunyadi, Hungarian sentence prosody and universal grammar: on the phonology-syntax interface. Frankfurt/Main: Lang, 2002.

[2] L. Varga, Intonation and Stress: evidence from Hungarian. Basingstoke and New York: Palgrave Macmillan, 2002.

[3] K. Szendrôi, "A stress-based approach to the syntax of hungarian focus," The Linguistic Review, vol. 20, pp. 37-78, 2003.

[4] I. Vogel and I. Kenesei, "The interface between phonology and other components of the grammar: The case of hungarian." Phonology Yearbook, vol. 4, pp. 243-263, 1987.

[5] _ "Syntax and semantics in phonology." in The PhonologySyntax Connection, S. Inkelas and D. Zec, Eds. Chicago: The University of Chicago Press, 1990.

[6] K. É. Kiss, Hungarian Syntax. Cambridge: Cambridge University Press, 2002.

[7] N. Chomsky and M. Halle, The Sound Pattern of English. New York: Harper and Row, 1968.

[8] J. M. Sadock and A. M. Zwicky, "Speech act distinctions in syntax," in Language Typology and Syntactic Description, T. Shopen, Ed. Cambridge University Press, Cambridge, 1985, pp. 155-196.

[9] E. König and P. Siemund, "Speech act distinctions in syntax," in Language Typology and Syntactic Description, Vol. 1, T. Shopen, Ed. Cambridge University Press, Cambridge, 2007, pp. 276-324.

[10] L. Kálmán, Magyar leíró nyelvtan 1. Mondattan. Budapest: Tinta Könyvkiadó, 2001, [Hungarian descriptive grammar 1. Syn$\operatorname{tax}]$.

[11] B. Gyuris and K. Mády, "Approaching the prosody of Hungarian wh-exclamatives," in VLLXX: Papers presented to László Varga on his 70th birthday, P. Szigetvári, Ed., 2013, http://seas3.elte.hu/tmp/vlfs/gyuris-mady.html.

[12] L. Mycock, "Prominence in Hungarian: the prosody-syntax connection," Transactions of the Philological Society, vol. 108, no. 3 , pp. 265-297, 2010.

[13] K. Mády, B. Gyuris, and A. Szalontai, "Phrase-initial boundary tones in hungarian interrogatives and exclamatives," in Proceedings of the Prosody-Discourse Interface Conference (IDP-2013), 2013, pp. 69-73.

[14] D. R. Ladd, Intonational phonology, 2nd ed. Cambridge: Cambridge University Press, 2008.

[15] 1. Varga, "Boundary tones and the lack of intermediate phrase in hungarian (revisiting the hungarian calling contour)," The Even Yearbook, vol. 9, pp. 1-27, 2010.

[16] M. Gósy and J. Terken, "Question marking in hungarian: Timing and height of pitch peaks," Journal of Phonetics, vol. 22, pp. 269 281, 1994.

[17] C. Draxler and K. Jänsch, "SpeechRecorder - a universal platform independent multi-channel audio recording software," in Proc. International Conference on Language Resources and Evaluation, Lissabon, 2004, pp. 559-562.

[18] K. Mády and F. Kleber, "Variation of pitch accent patterns in Hungarian," in Proc. 5th Speech Prosody Conference, Chicago, 2010, pp. $100924: 1-4$.

[19] K. Mády, “A fókusz prozódiai jelölése felolvasásban és spontán beszédben [prosodic marking of focus in read and spontaneous speech],' in Beszéd, adatbázis, kutatások, M. Gósy, Ed. Budapest: Akadémiai Kiadó, 2012, pp. 91-107. 